\title{
Advancing Oral Health Knowledge and Attitudes of Physician Assistant Students Using the Smiles for Life Oral Health Curriculum
}

Jennifer Forbes, MHS, PA-C; Talia Sierra, MPAS, PA-C; Jared Papa, MPAS, PA-C

BACKGROUND AND OBJECTIVES: The purpose of this study was to determine the effectiveness of the Society of Teachers of Family Medicine's Smiles for Life: A National Oral Health Curriculum on the knowledge and attitudes of physician assistant students regarding oral health.

METHODS: Seventy-two didactic year physician assistant students from one physician assistant program were surveyed to assess their knowledge and attitudes regarding oral health prior to starting the Smiles for Life oral health curriculum. The students were electronically surveyed a second time 1 week after completing all online modules in the Smiles for Life oral health curriculum.

RESULTS: Precourse and postcourse survey response rates were $57 \%$ and $36 \%$, respectively. The mean of the attitude statements increased from 3.20 on the precourse survey to 3.87 on the postcourse survey $(P=.0012)$. The mean number of correct responses on the knowledge questions increased from 6.83 on the precourse survey to 9.85 on the postcourse survey $(P<.0001)$.

CONCLUSIONS: Statistically significant improvements in the attitudes toward oral health and oral health knowledge of physician assistant students after completion of the Smiles for Life curriculum were observed. This study illustrates the effectiveness of the Smiles for Life curriculum as an interprofessional educational experience. This curriculum can be completed online and does not require faculty expertise in oral health, thus removing previously cited barriers to incorporating oral health into the physician assistant curriculum.

(Fam Med. 2018;50(10):775-8.)

doi: 10.22454/FamMed.2018.435186

ince the Surgeon General Report on Oral Health in America was released in 2000 revealing the existence of significant oral health disparities in America, there has been a greater emphasis on integrating oral health into medical education. ${ }^{1}$ Historically, oral health training in medical education was an area of knowledge deficit and diseases of the oral cavity were typically not addressed by nondental providers. ${ }^{2-4}$ More recently the link between oral health and many chronic systemic diseases has been established, and performing an oral assessment by nondental clinicians has gained importance as a necessary component of primary care. ${ }^{5,6}$

Many steps have been taken to address physicians' oral health knowledge deficit through training in medical school and residency., ${ }^{2,7}$ This issue has also been addressed in physician assistant (PA) education. Most PA programs have incorporated oral health education into the curriculum; however, a lack of available class time and lack of faculty with oral health content expertise are two barriers cited in programs not offering oral health education. ${ }^{8,9}$

Strategies for implementing oral health into the curriculum of medical and PA programs vary by school and the availability of resources. Interprofessional teaching with dental or dental hygiene programs, service learning activities, small group workshops, lectures, clinical skills lab, observed structured clinical examinations (OSCE), and an online curriculum are approaches that have been used and published in the literature. ${ }^{3-5,9-12}$ Many medical and PA programs use the Society of Teachers of Family Medicine's (STFM) Smiles

From Idaho State University, Pocatello, ID. 
for Life: A National Oral Health Curriculum as a component of their oral health curriculum.

The current Smiles for Life (SFL) curriculum consists of eight PowerPoint modules, each 45-minutes in length. ${ }^{13}$ The SFL curriculum is available free of charge. All of the modules can be completed online, or the curriculum can be presented in the classroom.

While acceptance and support for the SFL curriculum is substantial, there has not been a study evaluating the effectiveness of the SFL curriculum as a learning tool for PA students. ${ }^{13}$ The purpose of this study was to evaluate the effectiveness of the online SFL curriculum on the knowledge and attitude of PA students regarding oral health.

\section{Methods}

The survey instruments used in this study consisted of a precourse and postcourse survey. The surveys were administered to 72 didactic year PA students from one PA program via email using Qualtrics online survey software. ${ }^{14}$ All students had the opportunity to complete the precourse and postcourse surveys. The Idaho State University Institutional
Review Board determined the research proposal was exempt. Completion of the survey implied consent.

The precourse survey consisted of 13 multiple-choice questions selected from SFL module posttests and assessed PA students' baseline medical knowledge on oral health. There were also eight statements, developed by the authors, addressing PA students' attitudes toward oral health. Attitude statements were answered on a 5-point Likert scale, with 1 corresponding to "strongly disagree" and 5 to "strongly agree." The precourse survey was administered 1 week prior to the start of the SFL modules. The students were not permitted to review the answers from the knowledge questions on the survey, and they did not receive their scores. One week after completing all eight SFL modules using the online curriculum, a postcourse survey was administered. The postcourse survey was a replication of the precourse survey. Unpaired $t$-tests using MedCalc statistical software were performed to compare the means from the precourse and postcourse surveys. ${ }^{15}$

\section{Results}

Forty-one PA students (57\% response rate) completed the precourse survey and 26 (36\% response rate) completed the postcourse survey. One student completed the postcourse survey but did not complete the precourse survey. All completed precourse and postcourse surveys were included in the data analysis. The respondents' answers were not matched on the precourse and postcourse surveys. The mean for all attitude statements increased from 3.20 (SD 0.94) on the precourse survey to 3.87 (SD 0.46) on the postcourse survey, which is statistically significant $(P=.0012)$. Table 1 lists the individual attitude statements and shows the score for each individual statement.

The number of correct responses on the knowledge questions of the survey increased from a mean of 6.83 (SD 1.68) on the precourse survey to a mean of 9.85 (SD 2.78) on the postcourse survey. This represents a $23 \%$ increase in knowledge acquisition, which is highly statistically significant $(P<.0001)$. Table 2 lists the knowledge questions and the percentage each question was answered correctly on the pre- and postcourse surveys.

Table 1: Comparison of Pre-SFL and Post-SFL Curriculum Survey Attitudes

\begin{tabular}{|c|l|c|c|c|c|}
\hline & \multicolumn{1}{|c|}{ Survey Attitude Statements } & Pre-SFL Mean & Pre-SFL ST DEV & Post-SFL Mean $^{*}$ & Post-SFL ST DEV \\
\hline 1 & $\begin{array}{l}\text { I have confidence in my ability to perform } \\
\text { oral exams. }\end{array}$ & 2.27 & 0.83 & 3.19 & 0.92 \\
\hline 2 & $\begin{array}{l}\text { I have confidence in my ability to recognize } \\
\text { oral diseases. }\end{array}$ & 2.05 & 0.82 & 3.31 & 0.87 \\
\hline 3 & I can easily recognize normal oral anatomy. & 3.24 & 0.79 & 4.12 & 0.85 \\
\hline 4 & $\begin{array}{l}\text { I can accurately identify dental caries on an } \\
\text { oral exam. }\end{array}$ & 2.33 & 1.01 & 3.54 & 0.97 \\
\hline 5 & $\begin{array}{l}\text { I feel comfortable educating my patients } \\
\text { about proper oral health. }\end{array}$ & 3.10 & 1.08 & 3.96 & 0.64 \\
\hline 6 & $\begin{array}{l}\text { I expect to gain (or gained) knowledge and } \\
\text { skills from the Smiles for Life modules. }\end{array}$ & 4.44 & 0.59 & 4.12 & 0.72 \\
\hline 7 & $\begin{array}{l}\text { It is essential to include oral health training } \\
\text { in the PA program curriculum. }\end{array}$ & 4.20 & 0.67 & 4.31 & 0.69 \\
\hline 8 & $\begin{array}{l}\text { PAs should routinely incorporate brief oral } \\
\text { exams into their medical practice. }\end{array}$ & 4.00 & 0.67 & 4.40 & 3.87 \\
\hline & Overall Mean** & 3.20 & & & \\
\hline
\end{tabular}

*A 5-point Likert scale was used with 1 corresponding to "strongly disagree" and 5 to "strongly agree."

*** Statistically significant $P=.0012$. 
Table 2: Knowledge Question Comparison-Percent Answered Correctly

\begin{tabular}{|c|c|c|c|}
\hline & Survey Knowledge Questions & $\begin{array}{l}\text { Pre-SFL } \\
\text { Curriculum }\end{array}$ & $\begin{array}{l}\text { Post-SFL } \\
\text { Curriculum }\end{array}$ \\
\hline 1 & What is the full complement of adult teeth? & $75.61 \%$ & $92.31 \%$ \\
\hline 2 & Oral cancer is most commonly found in which area of the mouth? & $34.15 \%$ & $38.46 \%$ \\
\hline 3 & $\begin{array}{l}\text { The mother of a 9-month-old patient asks what causes early childhood caries. } \\
\text { Which of the following is the most accurate reply? }\end{array}$ & $90.24 \%$ & $92.31 \%$ \\
\hline 4 & Which of the following is a benefit of fluoride varnish? & $70.73 \%$ & $92 \%$ \\
\hline 5 & $\begin{array}{l}\text { A pregnant patient asks you for guidance about having dental treatment } \\
\text { during her pregnancy. What would you say? }\end{array}$ & $51.22 \%$ & $88.46 \%$ \\
\hline 6 & Which antibiotic is the drug of choice for intraoral infections? & $34.15 \%$ & $73.08 \%$ \\
\hline 7 & $\begin{array}{l}\text { Periodontal disease can be clinically distinguished from gingivitis in which of } \\
\text { the following ways? }\end{array}$ & $60.98 \%$ & $80.77 \%$ \\
\hline 8 & How can primary care clinicians prevent early childhood caries (ECC)? & $63.41 \%$ & $84.62 \%$ \\
\hline 9 & $\begin{array}{l}\text { What guidance about teething should a primary care clinician provide to a } \\
\text { toddler's caregiver? }\end{array}$ & $80.49 \%$ & $96.15 \%$ \\
\hline 10 & $\begin{array}{l}\text { What is the suggested common pathway linking chronic periodontitis and } \\
\text { conditions such as diabetes, coronary artery disease and adverse pregnancy } \\
\text { outcomes? }\end{array}$ & $24.39 \%$ & $65.38 \%$ \\
\hline 11 & Which of the following medications is linked to gingival hyperplasia? & $19.51 \%$ & $80.77 \%$ \\
\hline 12 & Which condition is associated with periodontal disease? & $21.95 \%$ & $61.54 \%$ \\
\hline \multirow[t]{2}{*}{13} & When should an avulsed tooth in a 3-year-old be optimally reimplanted? & $56.01 \%$ & $80.77 \%$ \\
\hline & Mean number of questions answered correctly* & 6.83 & 9.85 \\
\hline
\end{tabular}

*Statistically significant $P<.0001$.

\section{Discussion}

Numerous strategies have been used to incorporate oral health into medical education. While the optimal approach has not been established, many strategies include the SFL modules as one of the educational components. The purpose of this study was to determine the effectiveness of the online SFL curriculum as a learning tool for PA students. The results of this study show a statistically significant improvement in the attitudes and knowledge of PA students regarding oral health after completion of the online SFL curriculum. This was accomplished without the use of class time or faculty, removing two common barriers to incorporating oral health into the curriculum. This study illustrates the effectiveness of the online SFL curriculum as an interprofessional educational experience. Previous studies in medical education have shown the effectiveness of web-based didactic instruction for knowledge acquisition and this study supports those findings. ${ }^{16,17}$

This study has limitations. The sampling of students is from a single institution and there is not a nonintervention group. It is possible that the precourse survey acted as a stimulus for the students to learn the material and this was not evaluated. The knowledge questions were not validated; however, they were selected from the SFL modules posttests. The lack of data regarding long-term retention of knowledge and attitude change is also a limitation. Future studies could improve generalizability by including data from multiple institutions and measuring longterm retention through the administration of a final survey prior to graduation.

ACKNOWLEDGMENTS: Jennifer Forbes received the Smiles for Life Research Award in August 2017, after completion of the research study and acceptance of a poster presentation at an educational conference. A $\$ 600$ stipend from the Society of Teachers of Family Medicine was given to the author to support travel during the presentation of research results at the Association for Medical EduAMEE educational conference in Helsinki, Finland in September 2017.

Presentations: Association for Medical Education in Europe Educational Conference, September 2017, Helsinki, Finland.

American Academy of Physician Assistants National CME Conference, May 2017, Las Vegas, NV.

CORRESPONDING AUTHOR: Jennifer Forbes, MHS, PA-C, Clinical Assistant Professor, Idaho State University, 1311 E Central Dr, Meridian, ID 83646. ForbJenn@isu.edu.

\section{References}

1. US Department of Health and Human Services. Oral Health in America: A Report of the Surgeon General. Rockville, MD: National Institute of Dental and Craniofacial Research; 2000.

2. Douglass AB, Gonsalves W, Maier R, et al. Smiles for Life: A national oral health curriculum for family medicine. A model for curriculum development by STFM groups. Fam Med. 2007;39(2):88-90.

3. Anderson KL, Smith BS, Brown G. Using an expanded oral health curriculum by practicing physician assistants. J Physician Assist Educ. 2013;24(3):23-26.

4. Berkowitz O, Kaufman LB, Russell M. Introduction of an interprofessional oral health curriculum. J Physician Assist Educ. 2015;26(1):43-46. 
5. Griffin SO, Jones JA, Brunson D, Griffin PM, Bailey WD. Burden of oral disease among older adults and implications for public health priorities. Am J Public Health. 2012;102(3):411-418.

6. Krol DM. Educating pediatricians on children's oral health: past, present, and future. Pediatrics. 2004;113(5):e487-e492.

7. US Department of Health and Human Services, Health Resources and Services Administration. Integration of Oral Health and Primary Care Practice. Rockville, MD: US Department of Health and Human Services; 2014.

8. Jacques PF, Snow C, Dowdle M, Riley N, Mao $\mathrm{K}$, Gonsalves WC. Oral health curricula in physician assistant programs: a survey of physician assistant program directors. J Physician Assist Educ. 2010;21(2):22-30.

9. Langelier $\mathrm{MH}$, Glicken $\mathrm{AD}$, Surdu S. Adoption of oral health curriculum by physician assistant education programs in 2014. J Physician Assist Educ. 2015;26(2):60-69.
10. Nicely SL. Effects of a comprehensive oral health curriculum on knowledge, behavior, and attitude of physician assistant students. J Physician Assist Educ. 2016;27(2):73-76.

11. Silk H, O'Grady Stille S, Baldor R, Joseph E. Implementation of STFM's "Smiles for Life" oral health curriculum in a medical school interclerkship. Fam Med. 2009;41(7):487-491.

12. Bowser J, Sivahop J, Glicken A. Advancing oral health in physician assistant education: evaluation of an innovative interprofessional oral health curriculum. J Physician Assist Educ. 2013;24(3):27-30.

13. Society of Teachers of Family Medicine. Smiles for Life: A National Oral Health Curriculum 3rd Edition. http://www.smilesforlifeoralhealth. com/. Accessed September 28, 2017.

14. Qualtrics (statistical software). Provo, Utah: Qualtrics; 2018.

15. MedCalc (statistical software). Version 18. Ostend, Belgium: MedCalc; 2018.
16. Cook DA, Levinson AJ, Garside S, Dupras DM, Erwin PJ, Montori VM. Internet-based learning in the health professions: a meta-analysis. JAMA. 2008;300(10):1181-1196.

17. Ruiz JG, Mintzer MJ, Leipzig RM. The impact of E-learning in medical education. Acad Med. 2006;81(3):207-212. 